\title{
Long-distance ABA transport can mediate distal tissue responses by affecting local $A B A$ concentrations $^{\text {AA }}$
}

\author{
$\underset{\mathcal{U}}{\mathcal{U}}$ Wenrao $\mathrm{Li}^{1}$, Carlos de Ollas ${ }^{2 \dagger}$ and Ian C Dodd ${ }^{2 *}$ \\ 1. College of Life Sciences, Henan University, Kaifeng 475004, China, \\ 2. Plant \& Crop Sciences, Lancaster Environment Center, Lancaster University, Lancaster LA1 4YQ, United Kingdom. \\ $\because \quad{ }^{\dagger}$ Current address: Departamento de Ciencias Agrarias del Medio Natural. Universitat Jaume I, Spain \\ *Correspondence: Ian C Dodd (i.dodd@lancaster.ac.uk) \\ है doi: $10.1111 /$ jipb.12605
}

Abstract Environmental stresses that perturb plant water relations influence abscisic acid (ABA) concentrations, but it is unclear whether long-distance $A B A$ transport contributes to changes in local $A B A$ levels. To determine the physiological relevance of $A B A$ transport, we made reciprocal- and self-grafts of ABA-deficient flacca mutant and wild-type (WT) tomato plants, in which low phosphorus $(P)$ conditions decreased $A B A$ concentrations while salinity increased $A B A$ concentrations. Whereas foliar $A B A$ concentrations in the WT scions were rootstock independent under control conditions, salinity resulted in longdistance transport of ABA: flacca scions had approximately twice as much $A B A$ when grafted on WT rootstocks compared to flacca rootstocks. Root ABA concentrations were scion dependent: both WT and flacca rootstocks had less $A B A$ with the flacca mutant scion than with the WT scion under control conditions. In WT scions, whereas rootstock genotype had limited effects on stomatal conductance under control conditions, a flacca rootstock decreased leaf area of stressed plants, presumably due to attenuated root-to-shoot ABA transport. In flacca scions, a WT rootstock decreased stomatal conductance but increased leaf area of stressed plants, likely due to enhanced root-to-shoot $A B A$ transport. Thus, long-distance $A B A$ transport can affect responses in distal tissues by changing local ABA concentrations.

Edited by: Jianhua Zhu, University of Maryland, USA

Received Aug. 1, 2017; Accepted Oct. 16, 2017; Online on Oct. 20, 2017

FA: Free Access

\section{INTRODUCTION}

Abscisic acid (ABA) is synthesized in response to multiple abiotic stresses that alter tissue water status (Zhang et al. 2006). Local synthesis of ABA (as indicated $\mathcal{U}$ by enhanced expression of the NCED gene encoding the

tᄂ rate-limiting enzyme in ABA production; luchi et al. 2001; Speirs et al. 2013) has been observed in the leaves of well-watered plants exposed to high evaporative demand (McAdam et al. 2016b), detached leaves and roots allowed to dry on the laboratory bench (ZdunekZastocka and Sobczak 2013), as well as in the leaves and roots of plants exposed to drying soil (Speirs et al. 2013; Zdunek-Zastocka and Sobczak 2013). In addition to acting at the site of synthesis, ABA has also been suggested to act as a long-distance signal that moves from the roots via the xylem to the shoot, where it restricts transpirational water loss by closing the stomata (Schachtman and Goodger 2008; Shabala et al. 2016). However, reciprocal grafting studies using wild-type (WT) and ABA-deficient genotypes, which should diminish the long-distance transport of $A B A$, suggest a relatively limited role for root-synthesized $A B A$ in regulating gas exchange in the leaves of both Solanum lycopersicum (tomato) and Arabidopsis thaliana (Arabidopsis). For instance, soil drying induces normal levels of stomatal closure in WT tomato scions grafted to rootstocks of the ABA-deficient mutant sitiens (sit), in which any long-distance ABA signal is greatly reduced (Holbrook et al. 2002). Similarly, osmotic stress still induces stomatal closure in WT shoots grafted to rootstocks of the ABA-deficient 
mutant aba2-1 in Arabidopsis thaliana, while aba2-1 stomata fail to close regardless of their rootstock (Christmann et al. 2007). These results call into question the importance of long-distance ABA transport within the plant.

Other studies have shown that the relative effects of $A B A$ deficiency on stomatal responses, in reciprocally grafted WT and ABA-deficient genotypes, can vary according to the prevailing environmental conditions. For example, under high relative humidity, the ABAdeficient sit tomato rootstock did not influence stomatal conductance $\left(g_{s}\right)$ of WT scions (thus $g_{s}$ was independent of rootstock and root-to-shoot ABA transport), but under low relative humidity, a sit rootstock increased $g_{s}$ of WT scions by $37 \%$ compared with the WT self-grafts (indicating a significant effect of root-to-shoot $A B A$ transport). Conversely, under high relative humidity, a WT rootstock significantly decreased $g_{s}$ of sit scions compared to sit self-grafts indicating that enhanced $A B A$ transport from WT rootstocks could phenotypically revert an ABA-deficient scion, while the stomatal response of $A B A$-deficient scions was rootstock-independent under low relative humidity conditions (Jones et al. 1987). Thus root-to-shoot ABA transport can alter stomatal responses of both WT and ABA-deficient scions, but only under specific environmental conditions.

Whereas there are few such examples where an ABA-deficient rootstock increases $g_{s}$ of WT scions by attenuating $A B A$ transport from the roots, about half of the previous studies show a pronounced phenotypic reversion of stomatal behavior in ABA-deficient scions grafted to a WT rootstock due to enhanced $A B A$ transport from the WT rootstock (Albacete et al. 2015). Thus, it can be difficult to generalize the role of rootsupplied $A B A$ in regulating stomatal conductance. Similarly, grafting a WT scion onto an ABA-deficient tomato rootstock, flacca (flc), had no effect on leaf area, yet a WT rootstock substantially increased the leaf area of flc scions compared to flc self-grafts (Dodd et al. 2009). Again, this shows that it can be difficult to generalize the role of root-supplied $A B A$ in regulating leaf expansion, as the effects are scion-dependent. Thus, the effects of root-synthesized $A B A$ on shoot physiology (both stomatal conductance and growth) may depend on the specific stresses encountered by the plant, and on the scion ABA status.

While reciprocal grafting can elucidate the relative importance of root-to-shoot and shoot-to-root $A B A$ transport, hormone flow-modeling studies of ungrafted white lupin (Lupinus albus) plants identified environmental stresses in which these flows are especially important (Wolf et al. 1990). In non-salinized plants, $28 \%$ of the ABA flowing from the root to the shoot in the xylem originated in the roots (with the remainder determined to have been synthesized in the shoot, transported to the roots in the phloem, and then recycled via the xylem), while this was almost doubled in salinized plants. Since these results implied that the relative importance of rootsynthesized ABA was greater under salinity, this was tested by reciprocally grafting WT and flc tomato plants. Although rootstock did not affect the scion biomass of the non-salinized plants or WT scions grown under salt stress, a WT rootstock doubled the biomass of flc scions when these plants were salinized, indicating that the importance of root-synthesized $A B A$ varied according to scion ABA status (Chen et al. 2003). While these physiological effects were consistent with the changes in shoot $A B A$ concentration (since increased shoot $A B A$ concentration of the flc scions could be explained by increased root export of $A B A$ from WT rootstocks), scion $A B A$ status had no effect on root $A B A$ concentration, whether or not the plants were salinized (Chen et al. 2003). Since the local ABA concentrations did not always correlate with the tissue growth response, further work is required to reveal how different environmental stresses affect scion and rootstock contributions to the ABA concentrations of distal organs.

Historically, relatively few studies have considered the potential role of $A B A$ as a shoot-to-root signal regulating root growth and physiology (reviewed in Kudoyarova et al. 2015), in part due to the difficulties of sampling roots. Nevertheless, there is evidence that shoot-to-root ABA transport affects rootstock phenotypes. In reciprocally grafted WT and flc tomatoes, root biomass and $A B A$ concentration partially depend on shoot-to-root ABA transport (Chen et al. 2002). In reciprocally grafted flc and WT tomatoes, the initial stress-induced root $A B A$ accumulation was independent of the scion genotype, indicating limited $A B A$ transport from shoots to roots (Manzi et al. 2015). Subsequent root $A B A$ accumulation in WT rootstocks was attenuated by a flc scion, while a WT scion increased the $A B A$ concentration in flc rootstocks, indicating that root $A B A$ concentrations depend on shoot to root $A B A$ transport. These changes in root $A B A$ concentration are not explained by differences in root 
water relations (Manzi et al. 2015), although root ABA concentrations correlate with the water status of both detached roots (Cornish and Zeevaart 1985; Simonneau et al. 1998) and the roots of ungrafted plants (Zhang and Davies 1989; Puértolas et al. 2013). Resolving the relative importance of local versus systemic effects on root $A B A$ concentration in grafted plants is important, especially since $A B A$ increases root hydraulic conductance which can alter plant water relations (Thompson et al. 2007).

Most studies of root-shoot communication have imposed a single abiotic stress, but there is increasing interest in understanding plant responses to combined stresses (Mittler 2006; Atkinson and Urwin 2012; Zribi et al. 2012, 2014). A recent meta-analysis showed that low phosphorus $(P)$ conditions increase xylem $A B A$ concentrations more than other nutritional stresses, with additive effects caused by salinity and nutrient limitations (Peuke 2016). Although saline soils reduce $\mathrm{P}$ bioavailability (Xu et al. 2016), the physiological effects of combining these stresses were inconsistent (Grattan and Grieve 1999). Even in salinized tomato plants, shoot biomass was independent of substrate $\mathrm{P}$ concentration in one study (Mohammad et al. 1998), yet increasing $P$ concentrations increased salt tolerance in another (Awad et al. 1990). Thus, whether limited $P$ availability exacerbates plant responses to salinity is uncertain, as is the potential role of $A B A$ transport in mediating such interactions.

We hypothesize that the relative importance of rootto-shoot and shoot-to-root $A B A$ transport in mediating physiological responses (growth, stomatal conductance) and tissue ABA concentrations depends on the environmental stresses imposed. Thus, self- and reciprocally-grafted WT and ABA-deficient flacca tomato plants were grown under a factorial combination of salinity and low $\mathrm{P}$ to determine root and shoot growth and water relations, leaf area and stomatal conductance, and root, xylem sap and shoot $A B A$ concentrations.

\section{RESULTS}

Scion ABA status has dominant effects on shoot and root biomass

Compared with plants grown under the control conditions (high phosphorus, non-salinized), which had the highest shoot biomass, combined low $\mathrm{P}$ and salinity stress had a greater effect than either stress alone, with the low $\mathrm{P}$, salt, and combined stresses decreasing shoot biomass by $30 \%, 56 \%$, and $79 \%$, respectively (averaged across all graft combinations; Figure $1 \mathrm{~A}$ ). In all treatments, WT self-grafts had the highest shoot biomass. Shoot biomass was decreased in the (scion/rootstock) flc/WT and flc/flc plants by $39 \%$ and $60 \%$, respectively (averaged across all treatments), while the flc rootstock had no significant effect on shoot biomass of WT scions under any of the treatments. WT rootstocks increased the shoot biomass of the flc scions (except under the combined stress) by 70\% (averaged across the remaining treatments). Taken together, these results indicate that the scion genotype had a dominant effect on shoot biomass, although WT rootstocks stimulated the growth of the flc scions, except under combined low $\mathrm{P}$ and salinity stress.

Root biomass was decreased under low P stress, salt stress, and the combined stress by $33 \%, 49 \%$, and $66 \%$ (averaged across all graft combinations; Figure 1B), respectively, in comparison with the control conditions. Root biomass varied similarly to shoot biomass, as there was no difference in the root/shoot ratios between graft combinations. The root biomass of the WT selfgrafts was 2.4-fold higher than the flc self-grafts (averaged across treatments). The flc scion decreased the growth of the WT rootstock by $47 \%$ (averaged across all treatments), while a WT scion increased the growth of flc rootstocks by $60 \%$. Thus, the scion genotype had a dominant effect on root biomass.

\section{Rootstock genotype determines stomatal conductance $\left(g_{s}\right)$ and leaf area of flc scions}

Compared with the control conditions, combined low $P$ and salinity stress had a greater effect than either stress alone, since the low $\mathrm{P}$, salt, and the combined stresses decreased $g_{s}$ by $30 \%, 73 \%$, and $81 \%$, respectively, (averaged across all graft combinations; Figure $2 \mathrm{~A}$ ). Generally, the flc scions had a higher $g_{s}$ than the WT scions. A flc rootstock had no significant effect on the $g_{s}$ of WT scions, except under the control conditions (50\% increase compared with the WT self-grafts). By contrast, the WT rootstock significantly affected the $g_{s}$ of flc scions; minimal $(<10 \%)$ differences were observed in the non-salinized plants, whereas in salinized plants, a WT rootstock decreased the $g_{s}$ of flc scions by approximately $70 \%$ compared with the flc self-grafts. 

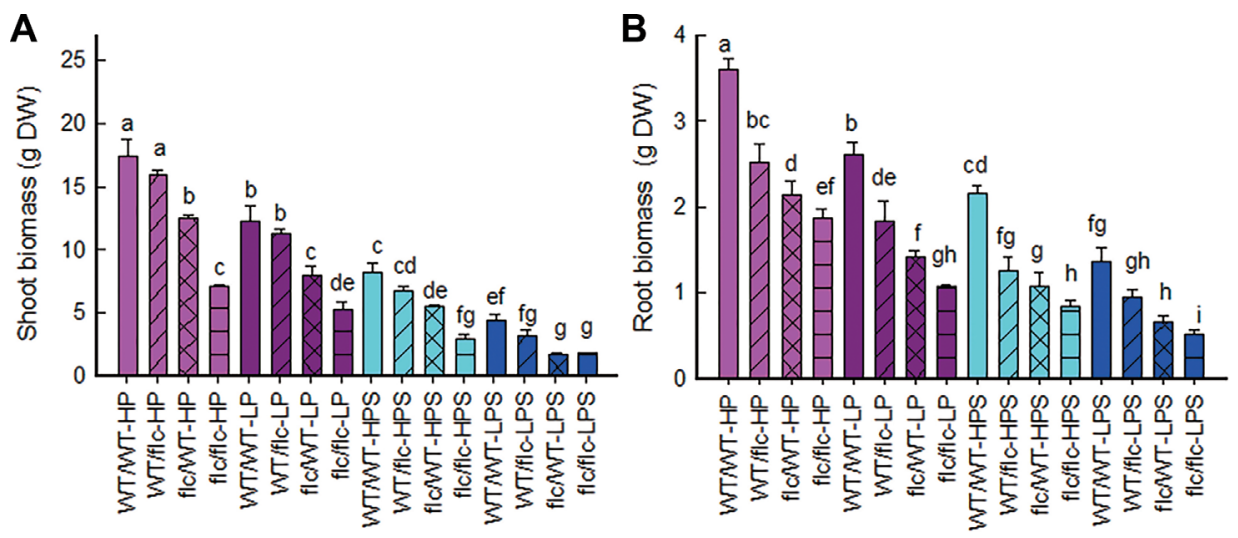

Figure 1. Shoot (A) and root (B) biomass in reciprocal and self-grafted wild-type (WT) and flacca (flc) tomato plants (indicated as scion/rootstock) grown under low (LP; $0.2 \mathrm{mmol} / \mathrm{L}$ ) or sufficient (HP $2.0 \mathrm{mmol} / \mathrm{L}$ ) phosphorus supply with (S) or without $75 \mathrm{mmol} / \mathrm{L} \mathrm{NaCl}$

(A) The shoot biomass of grafted combinations under different phosphate/salt conditions. (B) The root biomass of grafted combinations under different phosphate/salt conditions. Data are means $\pm S E$ of six replicates. Bars labeled with different letters are significantly different at $P<0.05$.

Overall, the effects of rootstock on $g_{s}$ were sciondependent, with limited effects in WT scions but pronounced stomatal closure of salinized flc/WT plants compared to flc self-grafts.

Leaf area decreased under low P stress, salt stress, and combined stress by $21 \%, 58 \%$, and $74 \%$, respectively, in comparison with the control conditions (averaged across all graft combinations; Figure $2 \mathrm{~B}$ ). While low $\mathrm{P}$ stress decreased leaf area similarly across all graft combinations, in salinized plants the severity of the growth inhibition increased as ABA levels declined. The
WT self-grafts had the largest leaf area under all treatments, with WT/flc, flc/WT, and flc/flc plants having $21 \%, 54 \%$, and $67 \%$ less leaf area, respectively (averaged across treatments). Although the WT self-grafts and the WT/flc plants had the same leaf area under control conditions, the flc rootstock resulted in a $27 \%$ smaller leaf area across all other treatments. The flc self-grafts and flc/WT plants had the same leaf area when grown under combined stress; however, the WT rootstock increased the leaf area of flc scions by an average of $47 \%$ in the other treatments. These experiments indicate
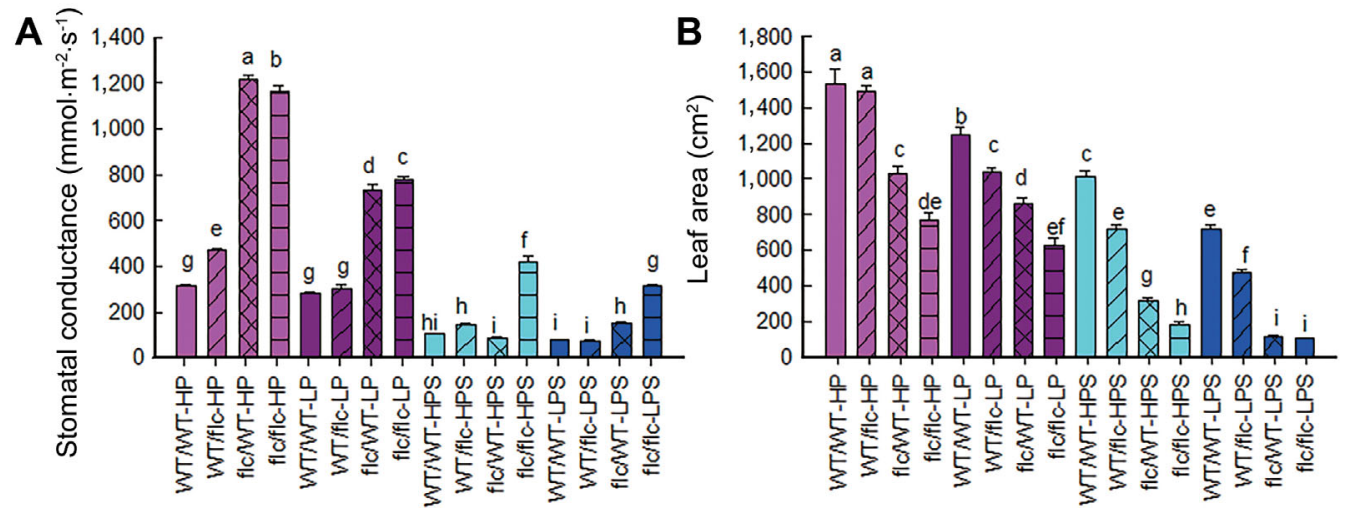

Figure 2. Single leaf stomatal conductance (A) and whole plant leaf area (B) in reciprocal and self-grafted wildtype (WT) and flacca (flc) tomato plants (indicated as scion/rootstock) grown under low (LP; $0.2 \mathrm{mmol} / \mathrm{L}$ or sufficient (HP; $2.0 \mathrm{mmol} / \mathrm{L}$ ) phosphorus supply with (S) or without $75 \mathrm{mmol} / \mathrm{L} \mathrm{NaCl}$

(A) The stomatal conductance of grafted combinations under different phosphate/salt conditions. (B) The leaf area of grafted combinations under different phosphate/salt conditions. Data are means $\pm S E$ of six replicates. Bars labeled with different letters are significantly different at $P<0.05$. 
that scion ABA status had a dominant effect on leaf area, although significant rootstock effects occurred in both the WT and flc scions.

\section{Scion ABA status generally determines plant water relations}

In isolation, low $\mathrm{P}$ stress did not significantly change leaf water potential $\left(\Psi_{\text {leaf }}\right)$, whereas salt stress decreased $\Psi_{\text {leaf }}$ by $0.45 \mathrm{MPa}$ (averaged across all graft combinations; Figure 3A); however, low $\mathrm{P}$ exacerbated the decrease in $\Psi_{\text {leaf }}$ induced by salinity by an additional $0.33 \mathrm{MPa}$ (averaged across all graft combinations). WT self-grafts always had a higher $\Psi_{\text {leaf }}$ than flc self-grafts (0.43 MPa and $0.86 \mathrm{MPa}$ higher in nonsalinized and salinized plants, respectively). In WT scions, $\Psi_{\text {leaf }}$ was rootstock-independent except under combined stress, where a flc rootstock decreased $\Psi_{\text {leaf }}$ by $0.12 \mathrm{MPa}$ compared with the WT self-grafts. In contrast, $\Psi_{\text {leaf }}$ was rootstock-dependent in the flc scions, with a WT rootstock increasing $\Psi_{\text {leaf }}$ by $0.30 \mathrm{MPa}$ (averaged across all treatments). Taken together, we conclude that the scion genotype had a dominant effect on $\Psi_{\text {leaf }}$, but a WT rootstock universally increased $\Psi_{\text {leaf }}$ of flc scions.

In non-salinized plants, all graft combinations had a similar root water potential ( $\Psi_{\text {root }}$; Figure 3B). Salt stress universally decreased $\Psi_{\text {root }}$, with combined stress further decreasing $\Psi_{\text {root }}$ by $0.21 \mathrm{MPa}$ (averaged across graft combinations). In salinized plants, the $\Psi_{\text {root }}$ of WT self-grafts was $0.46 \mathrm{MPa}$ higher than in the flc self-grafts. In WT rootstocks exposed to salinity, $\Psi_{\text {root }}$ was scion-dependent, with a flc scion decreasing $\Psi_{\text {root }}$ by $0.18 \mathrm{MPa}$ in comparison with the WT self-grafts. In flc rootstocks exposed to salinity, $\Psi_{\text {root }}$ was sciondependent; a WT scion increased the $\Psi_{\text {root }}$ by $0.48 \mathrm{MPa}$ compared with the flc self-grafts. Overall, the scion genotype had a dominant effect on $\Psi_{\text {root }}$.

\section{Long-distance $A B A$ transport affects local $A B A$ concentrations in both roots and shoots}

Low $P$ stress decreased foliar $A B A$ concentrations ([ABA $]_{\text {leaf }}$ ) by $25 \%$ compared with plants grown under the control conditions, while salt stress increased $[A B A]_{\text {leaf }}$ by $65 \%$ (averaged across all graft combinations; Figure $4 A)$. The $[A B A]_{\text {leaf }}$ of plants grown under combined stress was generally similar to that of plants grown in the control conditions (except for flc/WT plants, which showed a $65 \%$ increase under the combined stress). WT self-grafts had a 4-fold higher $[A B A]_{\text {leaf }}$ than the flc self-grafts (averaged across treatments), and the flc rootstock did not significantly influence the $[A B A]_{\text {leaf }}$ of the WT scions. By contrast, a WT rootstock significantly increased the $[A B A]_{\text {leaf }}$ of flc scions, by at least 1.4-fold and 2.8-fold in non-salinized and salinized plants, respectively. Although the scion genotype had a dominant effect on $[A B A]_{\text {leaf }}$, WT rootstocks significantly increased the $A B A$ concentration of flc scions, except under low $P$ stress.

Compared with the control conditions, low $\mathrm{P}$ stress decreased the $A B A$ concentration of root xylem sap $\left([\mathrm{ABA}]_{\text {xylem}}\right.$ ) by $43 \%$ (averaged across all graft combinations; Figure $4 \mathrm{~B}$ ). Salt stress resulted in an 18 -fold
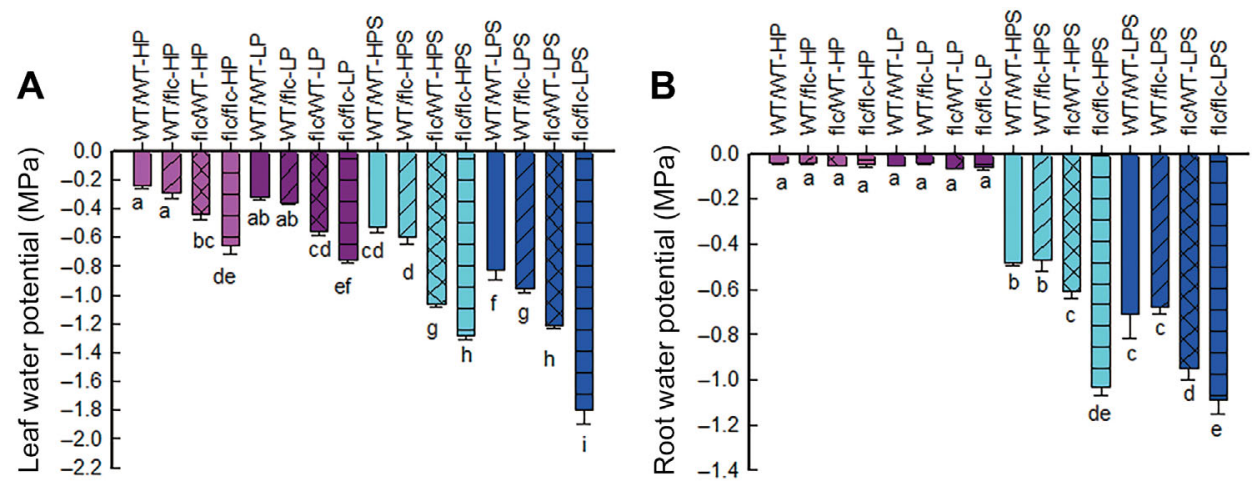

Figure 3. Leaf (A) and root (B) water potential in reciprocal and self-grafted wild-type (WT) and flacca (flc) tomato plants (indicated as scion/rootstock) grown under low (LP; $0.2 \mathrm{mmol} / \mathrm{L}$ ) or sufficient (HP; $2.0 \mathrm{mmol} / \mathrm{L}$ ) phosphorus supply with (S) or without $75 \mathrm{mmol} / \mathrm{L} \mathrm{NaCl}$

(A) The leaf water potential of grafted combinations under different phosphate/salt conditions. (B) The root water potential of grafted combinations under different phosphate/salt conditions. Data are means $\pm S E$ of six replicates. Bars labeled with different letters are significantly different at $P<0.05$. 

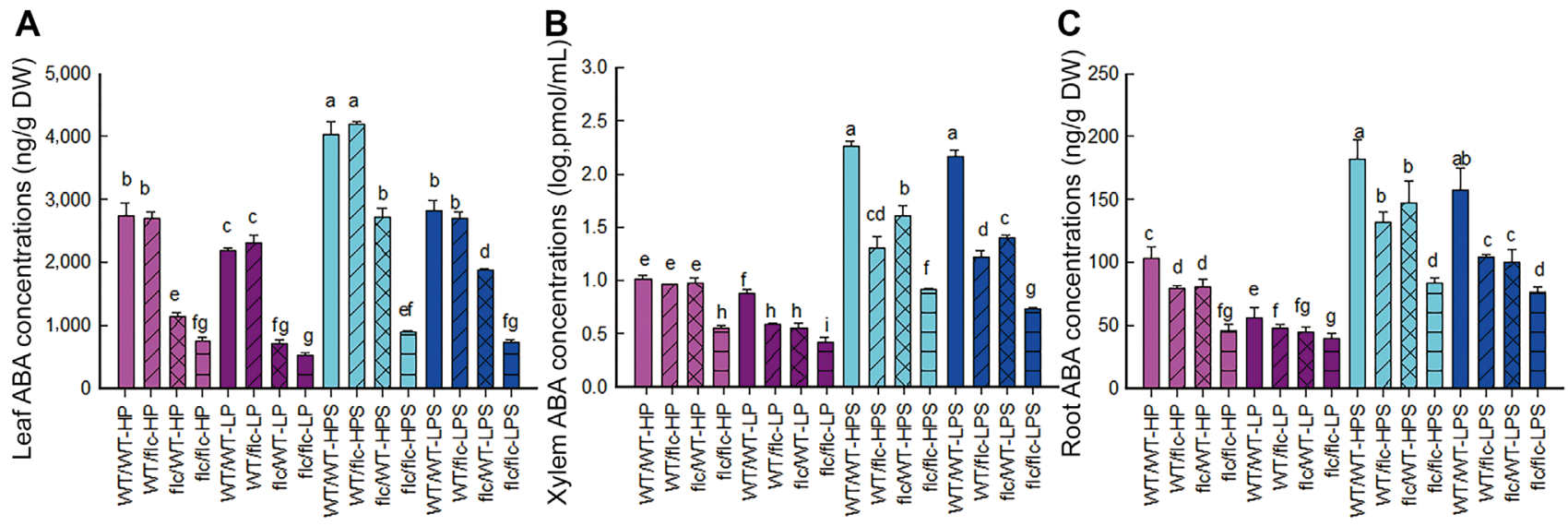

Figure 4. Leaf tissue (A), root xylem sap (B), and root tissue (C) ABA concentrations in reciprocal and self-grafted wild-type (WT) and flacca (flc) tomato plants (indicated as scion/rootstock) grown under low (LP; $0.2 \mathrm{mmol} / \mathrm{L}$ ) or sufficient (HP; $2.0 \mathrm{mmol} / \mathrm{L}$ ) phosphorus supply with (S) or without $75 \mathrm{mmol} / \mathrm{L} \mathrm{NaCl}$

(A) The leaf $A B A$ concentration of grafted combinations under different phosphate/salt conditions. (B) The xylem $A B A$ concentration of grafted combinations under different phosphate/salt conditions. (C) The root $A B A$ concentration of grafted combinations under different phosphate/salt conditions. Data are means $\pm S E$ of six replicates. Bars labeled with different letters are significantly different at $P<0.05$.

increase in the $[A B A]_{x y l e m}$ of WT self-grafts and a 2.9-fold average increase in the other graft combinations compared with plants grown in the control conditions. The combined stress attenuated this response however, generating a $28 \%$ lower $[A B A]_{x y l e m}$ (averaged across all graft combinations) than under salt stress alone. WT self-grafts had a 2.9-fold and a 24.7-fold higher $[A B A]_{x y l e m}$ than flc self-grafts in non-salinized and salinized plants, respectively. The flc scion did not affect the $[A B A]_{x y l e m}$ of $W T$ rootstocks under control conditions; however, across the three stress treatments, the flc scion decreased the $[A B A]_{x y l e m}$ of the WT rootstocks by an average of $71 \%$. WT scions universally increased $[A B A]_{x y l e m}$ of flc rootstocks (by 2.4-fold averaged across all treatments) compared with the flc self-grafts. Taken together, we found the rootstock genotype had a dominant effect on $[A B A]_{x y l e m}$, but this was influenced by the scion genotype, especially in the salinized plants.

Low $P$ stress decreased the root $A B A$ concentrations $\left([\mathrm{ABA}]_{\text {root }}\right)$ by $30 \%$ compared with the control conditions, while salt stress resulted in a 1.9-fold increase in the $[A B A]_{\text {root }}$ (averaged across all graft combinations; Figure $4 C$ ). The combined stress attenuated the saltinduced $A B A$ accumulation, with a $25 \%$ lower $[A B A]_{\text {root }}$ (averaged across all graft combinations) than under salt stress alone. WT self-grafts had approximately double the $[A B A]_{\text {root }}$ of the flc self-grafts. Universally, flc scions decreased the $[A B A]_{\text {root }}$ of WT rootstocks by an average of $25 \%$ (across all treatments) compared with the WT self-grafts, while a WT scion resulted in a 1.7 -fold increase in the $[A B A]_{\text {root }}$ of flc rootstocks (averaged across all treatments) compared with the flc self-grafts. Thus, although the rootstock genotype had a dominant effect on $[A B A]_{\text {root }}$, the scion genotype also had significant effects.

\section{Tissue ABA status had limited effects on tissue element concentrations}

In comparison with plants grown in the control conditions, low $\mathrm{P}$ stress decreased leaf and root $\mathrm{P}$ concentrations $\left([\mathrm{P}]_{\text {leaf }}\right.$ and $\left.[\mathrm{P}]_{\text {root }}\right)$ by $57 \%$ and $76 \%$, respectively, (averaged across all graft combinations; Table S1). Salt stress resulted in a 1.7-fold increase in the $[\mathrm{P}]_{\text {leaf }}$ and $[\mathrm{P}]_{\text {root }}$ of plants with WT scions (averaged across both tissues), but had no effect on $[P]_{\text {leaf }}$ and $[P]_{\text {root }}$ of plants with flc scions. Under the combined stress, $[P]_{\text {leaf }}$ and $[P]_{\text {root }}$ values were similar to those of plants grown under low $P$ stress. The ABA status of the scion had no consistent effect on the $[P]_{\text {leaf; }}$, however, the $[\mathrm{P}]_{\text {root }}$ of plants with flc scions was generally higher, with an average 1.4-fold increase relative to the WT scions (averaged across all treatments and graft combinations). Overall, the tissue $P$ concentration was consistent with the $\mathrm{P}$ treatment applied, whereas 
salt stress increased $P$ accumulation. Leaf and root $A B A$ status had no consistent effect on $[P]_{\text {leaf }}$ and $[P]_{\text {root }}$.

In non-salinized plants, leaf and root Na concentrations $\left([\mathrm{Na}]_{\text {leaf }}\right.$ and $[\mathrm{Na}]_{\text {root }}$ ) were similar between graft combinations and generally did not exceed $5 \mathrm{mg} \cdot \mathrm{kg}^{-1}$ dry weight (DW), although the $[\mathrm{Na}]_{\text {root }}$ of WT/flc plants under the control conditions was $13 \mathrm{mg}$ $\cdot \mathrm{kg}^{-1}$ DW (Table S2). Salinity increased [Na] leaf and $[\mathrm{Na}]_{\text {root }}$ by 6.5 -fold and 4.3-fold, respectively, (averaged across graft combinations and $P$ levels), with consistent effects across $\mathrm{P}$ levels. Although the $[\mathrm{Na}]_{\text {leaf }}$ of salinized WT self-grafts and the $[\mathrm{Na}]_{\text {root }}$ of salinized flc self-grafts were each approximately half that of the other graft combinations, generally tissue ABA status did not affect sodium accumulation.

\section{Correlation analysis reveals unifying behavior across multiple graft combinations}

Across all treatments and graft combinations, leaf area decreased linearly with $\Psi_{\text {leaf }}$ (Figure 5A). Leaf area was not correlated with $[P]_{\text {leaf }}$ (Figure $5 B$ ), but increased linearly with $[A B A]_{\text {leaf, }}$ with unique relationships observed in the salinized and non-salinized plants (Figure 5C).

Within each salt treatment, $g_{s}$ increased linearly as $\Psi_{\text {leaf }}$ declined (Figure 6A), although these variables were not significantly correlated across all treatments and graft combinations. Stomatal conductance was not correlated with $[\mathrm{P}]_{\text {leaf }}$ (Figure $6 \mathrm{~B}$ ), but decreased as $[A B A]_{\text {leaf }}$ increased, although this relationship was more sensitive in non-salinized plants (Figure 6C). Although $g_{s}$ was correlated with $[A B A]_{\text {root }},[A B A]_{\text {xylem }}$, and $[A B A]_{\text {leaf }}$, the latter variable explained more of the variance in $g_{s}$ than the other two (Table S3).

In plants grown under low $\mathrm{P}$ conditions, there was no relationship between root biomass and $[P]_{\text {root }}$ (Figure $7 \mathrm{~A}$ ), or shoot biomass and $[P]_{\text {leaf }}$ (Figure $7 C$ ). In plants grown with an optimal $P$ supply, root biomass increased as $[P]_{\text {root }}$ decreased (Figure $7 \mathrm{~A}$ ) while shoot biomass increased as $[P]_{\text {leaf }}$ decreased (Figure $7 C$ ). Within each salt treatment, root biomass increased with $[A B A]_{\text {root }}$ (Figure $7 B$ ) and shoot biomass increased with $[A B A]_{\text {leaf }}$ (Figure 7D).

The above findings highlighted the importance of understanding the regulation of tissue $A B A$ concentrations. Higher $[A B A]_{\text {leaf }}$ was correlated with higher $\Psi_{\text {leaf }}$ in both salinized and non-salinized plants, with salinity decreasing the $\Psi_{\text {leaf }}$ by $1.02 \mathrm{MPa}$ at the same
$[A B A]_{\text {leaf }}$ (Figure $\left.8 A\right)$. Although $[A B A]_{\text {root }}$ was independent of $\Psi_{\text {root }}$ in non-salinized plants, a higher $[A B A]_{\text {root }}$ was correlated with a higher $\Psi_{\text {root }}$ (Figure $8 C$ ) in salinized plants. Leaf and root $\mathrm{P}$ concentrations were not correlated with their respective $A B A$ concentrations (Figure 8B, D). Taken together, these correlations suggest that endogenous $A B A$ concentrations regulate the water status of local tissues.

\section{DISCUSSION}

Since there has been considerable controversy on the physiological importance of root-sourced $A B A$ in plants responses to environmental stresses that are expected to stimulate root ABA biosynthesis (e.g. Holbrook et al. 2002; Manzi et al. 2015), WT and ABA-deficient tomato plants were self- and reciprocally-grafted and grown under factorial combinations of salt and low $\mathrm{P}$ stress. Even though the scion genotype moderated rootstock ABA status in reciprocally grafted plants, many physiological variables (shoot biomass, leaf area, leaf water potential and $[A B A]_{\text {leaf }}$ ) were rootstock-dependent even in WT (ABA-replete) scions, implying pronounced effects of root-to-shoot $A B A$ transport. This conclusion was confirmed by comprehensive profiling of leaf, root and xylem sap ABA concentrations (Figure 4), which established that long-distance $A B A$ transport (in both directions) can mediate distal tissue responses by affecting local ABA concentrations.

Combining our data with previous reports of selfand reciprocally grafted WT and ABA-deficient tomatoes (Figure 9D-F; Table S4) is timely, given the paradigm shifts in the perceived physiological importance of long-distance $A B A$ transport. Currently, rootstock $A B A$ status is believed to have negligible effects on $g_{s}$ and $[A B A]_{\text {leaf }}$ (Holbrook et al. 2002; Christmann et al. 2007), and scion ABA status is thought to regulate $[A B A]_{\text {root }}$ (Manzi et al. 2015; McAdam et al. 2016a). We performed a meta-analysis of the effects of a distal organ on local $A B A$ concentrations (Figure 9A, B) and the concomitant physiological effects (Figure $9 C$ ) in tomato, which highlighted three main conclusions. First, ABA-deficient scions decrease the $A B A$ concentrations of WT rootstocks, while WT scions increase the $A B A$ concentrations of ABA-deficient rootstocks. Second, $A B A$-deficient rootstocks have no significant influence on 

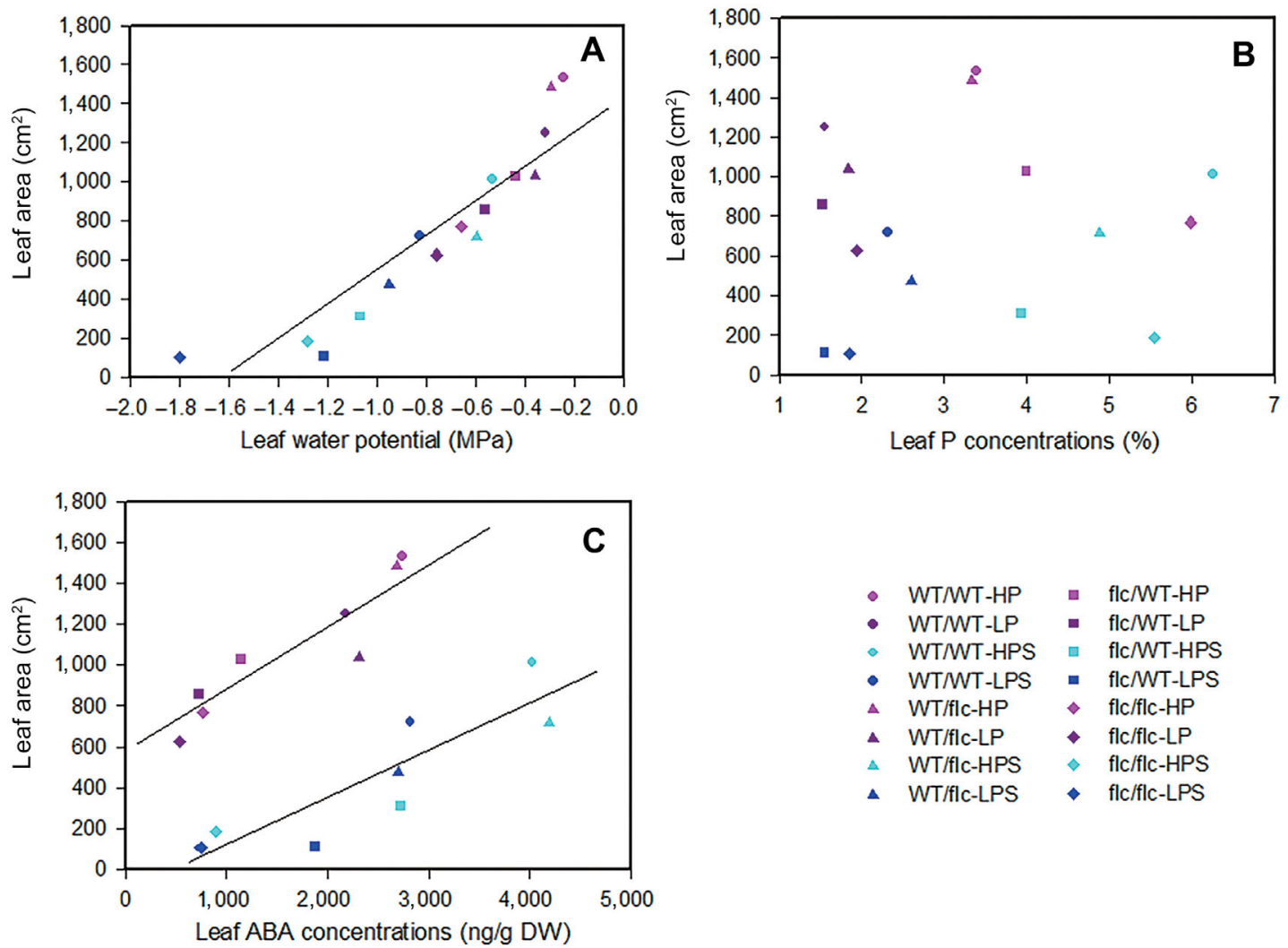

Figure 5. Relationships between leaf area and leaf water potential (A), leaf phosphorus concentration (B), and leaf $A B A$ concentration (C) in reciprocal and self-grafted wild-type (WT) and flacca (flc) tomato plants (indicated as scion/rootstock) grown under low (LP; $0.2 \mathrm{mmol} / \mathrm{L}$ ) or sufficient (HP; $2.0 \mathrm{mmol} / \mathrm{L}$ ) phosphorus supply with (S) or without $75 \mathrm{mmol} / \mathrm{L} \mathrm{NaCl}$

(A) Relationships between leaf area and leaf water potential. (B) Relationships between leaf area and leaf phosphorus concentration. (C) Relationships between leaf area and leaf ABA concentration. Each point represents a treatment $\times$ graft combination, and linear regressions were fitted across all points $(\mathbf{A})$ and by salt concentration (C) when $P<0.05$

the ABA concentrations of WT scions, while WT rootstocks significantly increase the $A B A$ concentrations of ABA-deficient scions. Third, ABA-deficient rootstocks rarely affect the $g_{s}$ of WT scions, while WT rootstocks typically decrease the $g_{s}$ of ABA-deficient scions. Thus, while the effects of root-to-shoot (and shoot-to-root) ABA transport may depend on environmental stress(es) (Jones et al. 1987; Albacete et al. 2015), we found that the responses were surprisingly consistent (Figure 9A-C), despite different environmental stresses having very different effects on tissue water relations (Figure 3).

\section{Physiological responses to $\mathbf{P}$ deprivation are independent of $\mathrm{ABA}$}

Contrary to previous studies where limited $P$ increased $[A B A]_{\text {leaf }}$ (Jeschke et al. 1997; Rothwell et al. 2015), we found that low $P$ decreased $[A B A]_{\text {leaf }}$ and $[A B A]_{x y l e m}$ in all graft combinations (Figure 4), which may result from changes in $A B A$ biosynthesis, degradation, or long-distance transport (Jeschke et al. 1997; Peuke 2016). The decreased root hydraulic conductance of P-deprived plants (Radin and Matthews 1989) should decrease leaf turgor, thereby stimulating leaf $A B A$ accumulation, but no change in $\Psi_{\text {leaf }}$ was detected in our study (Figure 3A). Nevertheless, limited ABA accumulation (1.7-fold increase) in P-deficient castor bean leaves was attributed to a high net degradation of ABA (Jeschke et al. 1997). Since $P$ deprivation in isolation did not change $\Psi_{\text {leaf }}$ and $\Psi_{\text {root }}$ (Figure 3), a possible increase in $A B A$ degradation without a corresponding turgor-mediated increase of $A B A$ biosynthesis supports a model in which limited $P$ 

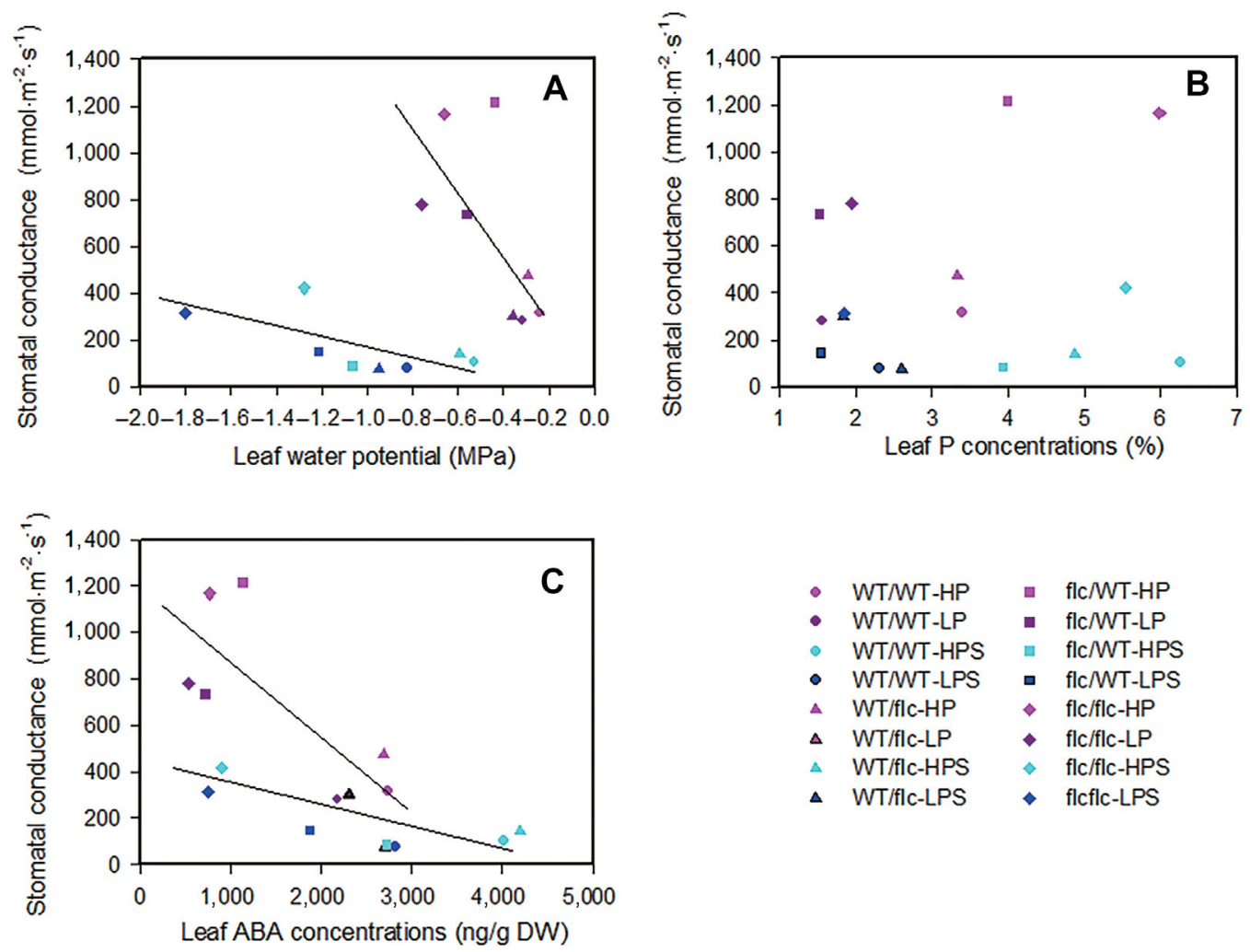

\begin{tabular}{|c|c|c|c|}
\hline$\bullet$ & WTMT-HP & घ & flc/WT-HP \\
\hline • & WTMT-LP & घ & flc $/ W T$-LP \\
\hline$\bullet$ & WTMT-HPS & $\square$ & flc/WT-HPS \\
\hline$\bullet$ & WTMT-LPS & घ & flc/WT-LPS \\
\hline$\Delta$ & WT/flc-HP & $\bullet$ & flc/flc-HP \\
\hline$\Delta$ & WT/flc-LP & $\bullet$ & $\mathrm{flc} / \mathrm{flc}-\mathrm{LP}$ \\
\hline$A$ & WT/flc-HPS & $\bullet$ & flc/flc-HPS \\
\hline & WT/flc-LPS & $\diamond$ & flcflc-LPS \\
\hline
\end{tabular}

Figure 6. Relationships between stomatal conductance and leaf water potential (A), leaf phosphorus concentration (B), and leaf ABA concentration (C) in reciprocal and self-grafted wild-type (WT) and flacca (flc) tomato plants (indicated as scion/rootstock) grown under low (LP; $0.2 \mathrm{mmol} / \mathrm{L}$ ) or sufficient (HP; $2.0 \mathrm{mmol} / \mathrm{L}$ ) phosphorus supply with (S) or without $75 \mathrm{mmol} / \mathrm{L} \mathrm{NaCl}$

(A) Relationships between stomatal conductance and leaf water potential. (B) Relationships between stomatal conductance and leaf phosphorus concentration. (C) Relationships between stomatal conductance and leaf ABA concentration. Each point represents a treatment $\times$ graft combination, and linear regressions were fitted by salt concentration $(\mathbf{A}, \mathbf{C})$ when $P<0.05$.

availability does not directly stimulate $A B A$ accumulation, but rather indirectly causes it as a side-effect of decreased turgor.

$P$ deprivation decreased the shoot and root biomass of all graft combinations (Figure 1). Linear and positive relationships between the root biomass and $[A B A]_{\text {root }}$ (Figure $7 \mathrm{~B}$ ), and shoot biomass and $[A B A]_{\text {leaf }}$ (Figure $7 D$ ), indicate that local $A B A$ accumulation maintains growth. This growth may be at least partially maintained by limiting the production of the growth inhibitor ethylene (Sharp et al. 2000; Dodd et al. 2009), which could be stimulated by P deprivation (García et al. 2015). Similarly, the positive relationship between $[A B A]_{\text {leaf }}$ and leaf area (Figure $5 \mathrm{C}$ ) may be accounted for by stress-enhanced ethylene evolution regulating tomato leaf expansion (Sobeih et al. 2004).
Direct ABA-mediated growth maintenance appears to be more important than any possible stomatal limitation of photosynthesis induced by $\mathrm{P}$ deprivation (Fujita et al. 2003; Rothwell et al. 2015). Although decreased $g_{s}$ correlated with suboptimal plant $P$ concentrations under well-watered conditions (Biddinger et al. 1998; Rothwell et al. 2015), we found that $g_{s}$ was independent of $P_{\text {leaf }}$ (Figure 6B). Under both $P$ treatments, the higher $g_{s}$ (and lower $\Psi_{\text {leaf }}$ ) of the flc self-grafts suggests that $g_{s}$ regulates $\Psi_{\text {leaf }}$ (Figure $6 \mathrm{~A}$ ), as previously reported for these graft combinations (Dodd et al. 2009) and for reciprocally grafted WT and strigolactone-deficient tomato plants (Visentin et al. 2016). Foliar ABA accumulation was previously reported to correlate with low-P-induced stomatal closure (Radin 1984; Rothwell et al. 2015). Although $[A B A]_{\text {leaf }}$ 

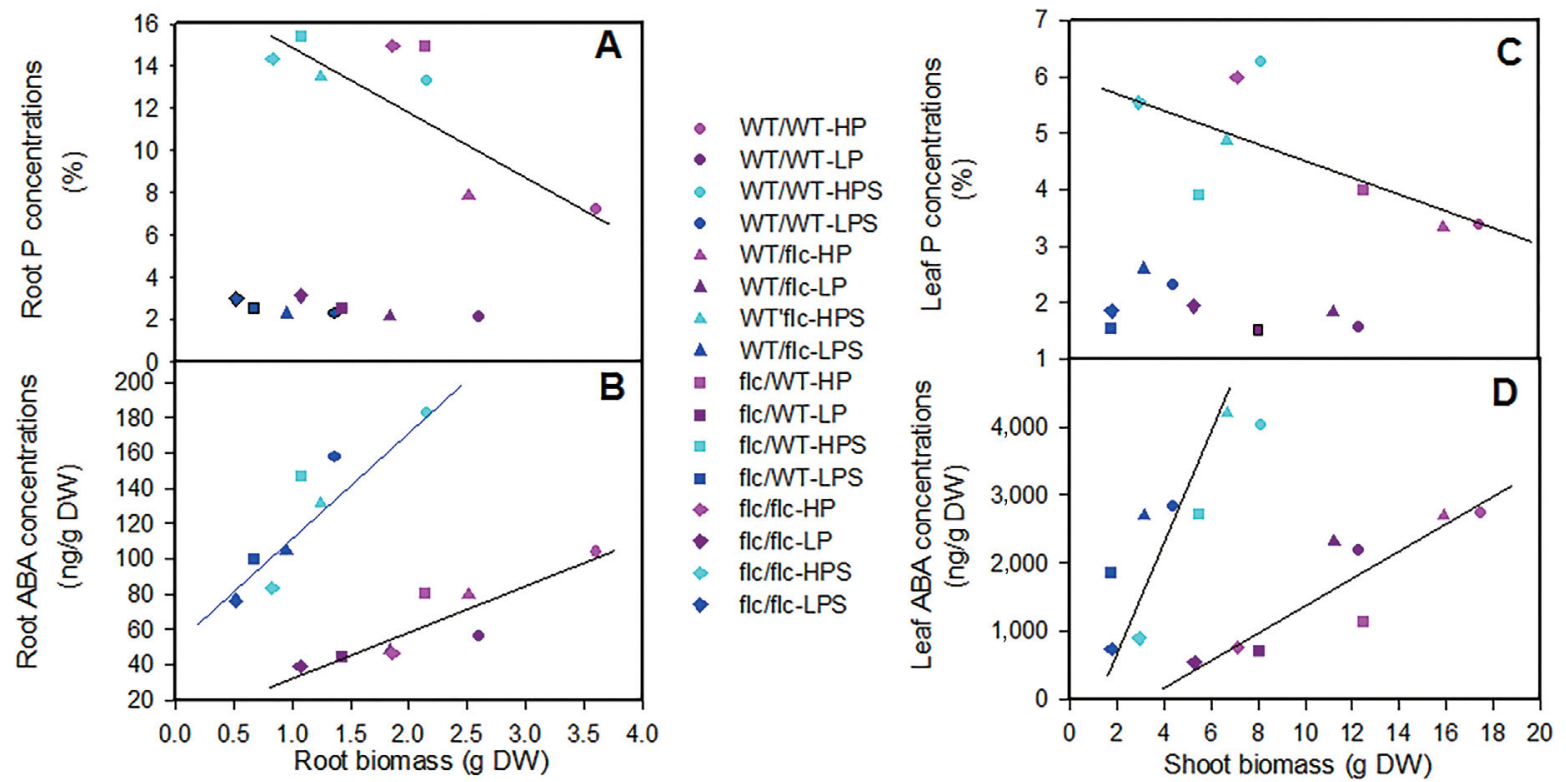

Figure 7. Relationships between root biomass and root phosphorus concentration (A) and root $A B A$ concentration (B), and between shoot biomass and leaf phosphorus concentration (C) and leaf ABA concentration (D) in reciprocal and self-grafted wild-type (WT) and flacca (flc) tomato plants (indicated as scion/rootstock) grown under low (LP; $0.2 \mathrm{mmol} / \mathrm{L}$ ) or sufficient (HP; $2.0 \mathrm{mmol} / \mathrm{L}$ ) phosphorus supply with (S) or without $75 \mathrm{mmol} / \mathrm{L}$ $\mathrm{NaCl}$

(A) Relationships between root biomass and root phosphorus concentration. (B) Relationships between root biomass and root ABA concentration. (C) Relationships between shoot biomass and leaf phosphorus concentration. (D) Relationships between shoot biomass and leaf $A B A$ concentration. Each point represents a treatment $\times$ graft combination, and linear regressions were fitted by $\mathrm{P}$ level $(\mathbf{A}, \mathbf{C})$ and by salt concentration (B, D) when $P<0.05$.

determined the maximal $g_{s}$ (Figure 6C), we found that low $P$ decreased $g_{s}$ and $[A B A]_{\text {leaf }}$ in all graft combinations involving flc as either the rootstock or the scion, suggesting that other phytohormones (MartínezAndújar et al. 2017) mediate stomatal responses to $P$ status.

\section{Physiological responses to salinity are independent of ABA}

As expected, when plants were grown under optimal $P$ supply, salinity increased the $[A B A]_{\text {leaf }}$ and $[A B A]_{\text {xylem }}$ of all graft combinations (except flc self-grafts), while increasing the $[A B A]_{\text {root }}$ of all graft combinations (Figure 4). The salinity-induced ABA accumulation in the roots of flc self-grafts contradicts the lack of response in observed in other studies using self-grafted flc tomato plants (Chen et al. 2003; $200 \mathrm{mmol} / \mathrm{L} \mathrm{NaCl}$ ), as well as those observed in ungrafted plants of the ABAdeficient notabilis tomato mutant (Mulholland et al. 2003; <120 mmol/L NaCl). This result is particularly surprising because flc is deficient in the root aldehyde oxidase activity that catalyzes the penultimate stage of ABA biosynthesis (Sagi et al. 1999). Nevertheless, flc accumulates trans-ABA alcohol (Linforth et al. 1987) which can be converted via a shunt pathway to $A B A$ (Rock et al. 1991), which seems to have been especially active in the salinized flc plants. While this root $A B A$ accumulation indicates local root $A B A$ synthesis in response to decreased $\Psi_{\text {root }}$ (Figure $3 B$ ) or the accumulation of ionic factors $\left(\mathrm{Na}^{+}\right.$and $\mathrm{Cl}^{-}$) (Table S2), pronounced shoot-to-root $\mathrm{ABA}$ transport also augmented the $[A B A]_{\text {root }}$ of WT/flc plants. Similarly, a flc scion diminished root $A B A$ accumulation of WT rootstocks, indicating that the $[A B A]_{\text {root }}$ partially depends on the import of $A B A$ from the shoot.

Salt-induced foliar $A B A$ accumulation in tomato (Albacete et al. 2008; Figure $4 \mathrm{~A}$ here) may result from local ABA biosynthesis in response to decreased $\Psi_{\text {leaf }}$ (Figure $3 \mathrm{~A}$ ) or root $\mathrm{ABA}$ export (Figure $4 \mathrm{~B}$ ). A previous study reported that WT self-grafts accumulate twice as 
much ABA in their leaves as WT/sit plants during soil drying, indicating the importance of root $A B A$ export, since $[A B A]_{\text {xylem }}$ was $70 \%$ lower in the $\mathrm{WT} /$ sit plants (Holbrook et al. 2002). Conversely, root ABA export did not affect the $[A B A]_{\text {leaf }}$ of WT scions but substantially altered the $[A B A]_{\text {leaf }}$ of flc scions (cf. Figure $4 A, B$ ). The relative importance of foliar $A B A$ biosynthesis versus root $A B A$ export in determining $[A B A]_{\text {leaf }}$ may therefore vary according to the graft combination.

The positive relationships between root and shoot biomass and their respective $A B A$ concentrations (Figure $7 B, D$ ) suggest that $A B A$ accumulation is necessary to maintain growth in salinized plants. Although salinity induced root and leaf $A B A$ accumulation and decreased $g_{s}$ (Figures $2 \mathrm{~A}, 6 \mathrm{C}$ ), $\Psi_{\text {leaf }}$ and $\Psi_{\text {root }}$ still decreased in these plants (Figure 3). Nevertheless, absolute $\Psi_{\text {leaf }}$ values are unlikely to directly affect growth inhibition, since all graft combinations showed similar salt-induced growth inhibition despite large differences $(0.29-0.63 \mathrm{MPa})$ in $\Psi_{\text {leaf }}$ (Figure $3 \mathrm{~A}$ ). Moreover, since $\Psi_{\text {leaf }}$ increased with $[\mathrm{ABA}]_{\text {leaf }}$ in unique linear relationships according to salt treatment (Figure $8 \mathrm{~A})$, and since $\Psi_{\text {root }}$ increased linearly with $[\mathrm{ABA}]_{\text {root }}$ in salinized plants (Figure $8 C$ ), leaf and root $A B A$ concentrations could instead regulate tissue water status by controlling stomatal behavior (Figure 6A, C).

There was limited variation in the plant $\mathrm{Na}^{+}$ concentrations between graft combinations (Table S2), as reported previously (Chen et al. 2003), which was consistent with the similar salt-induced growth inhibition in all graft combinations. Our results (Figure 1) corroborate reports (Chen et al. 2003; Mäkelä et al. 2003; Mulholland et al. 2003) that the shoot biomass response to salinity was generally $A B A$-independent, although concurrent salt stress and high evaporative demand of ABA-deficient plants desiccated their leaves (Mäkelä et al. 2003) and thus exacerbated their saltinduced growth inhibition compared to WT plants.
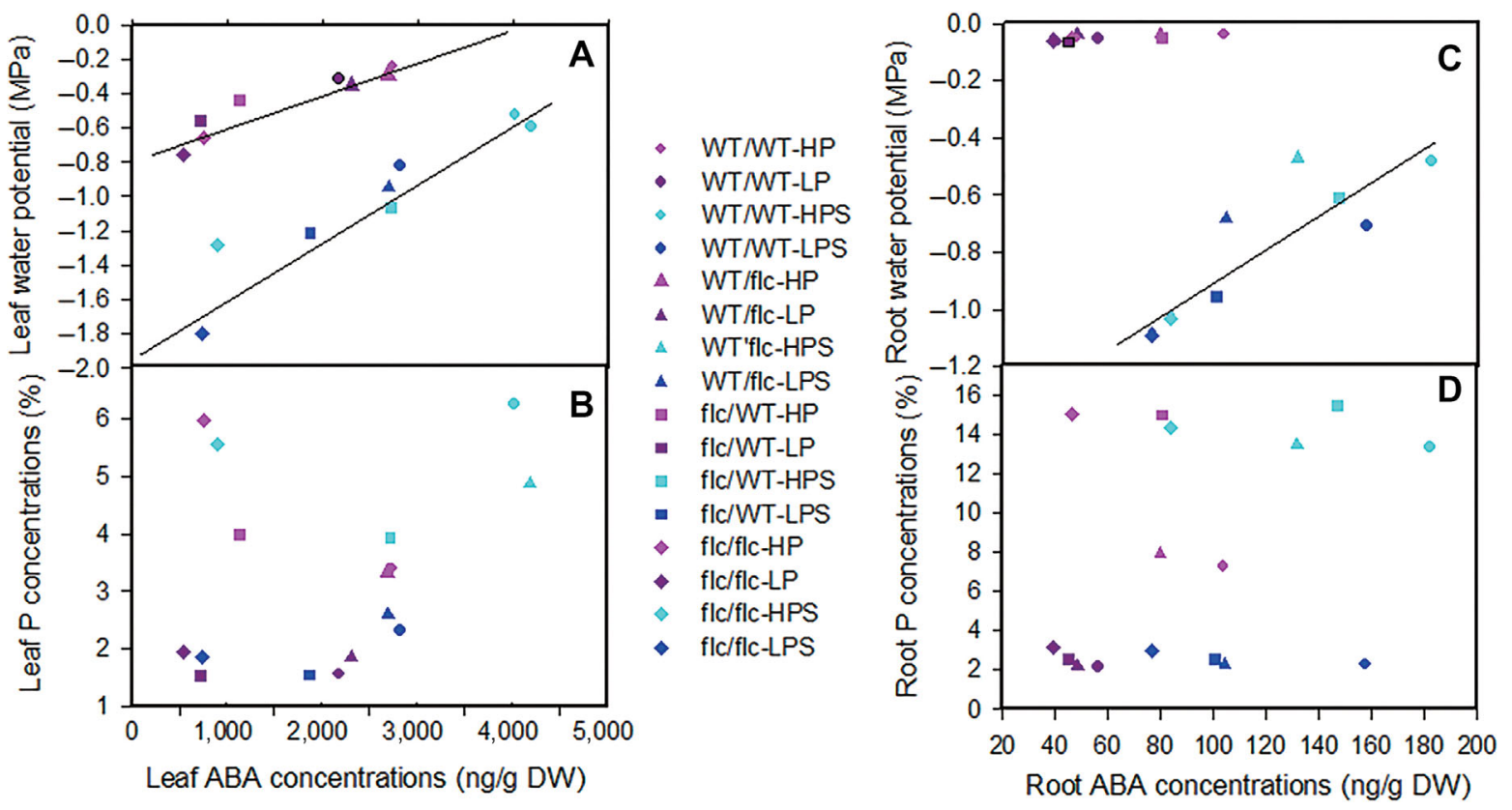

Figure 8. Relationships between leaf $A B A$ concentration and leaf water potential (A) and leaf phosphorus concentration (B), and between root $A B A$ concentration and root water potential (C) and root phosphorus concentration (D) in reciprocal and self-grafted wild-type (WT) and flacca (flc) tomato plants (indicated as scion/ rootstock) grown under low (LP; $0.2 \mathrm{mmol} / \mathrm{L}$ ) or sufficient (HP; $2.0 \mathrm{mmol} / \mathrm{L}$ ) phosphorus supply with (S) or without $75 \mathrm{mmol} / \mathrm{L} \mathrm{NaCl}$

(A) Relationships between leaf ABA concentration and leaf water potential. (B) Relationships between leaf ABA concentration and leaf phosphorus concentration. (C) Relationships between root $A B A$ concentration and root water potential. (D) Relationships between root $A B A$ concentration and root phosphorus concentration. Each point represents a treatment $\times$ graft combination, and linear regressions were fitted by salt concentration $(\mathbf{A}, \mathbf{C})$ when $P<0.05$ 

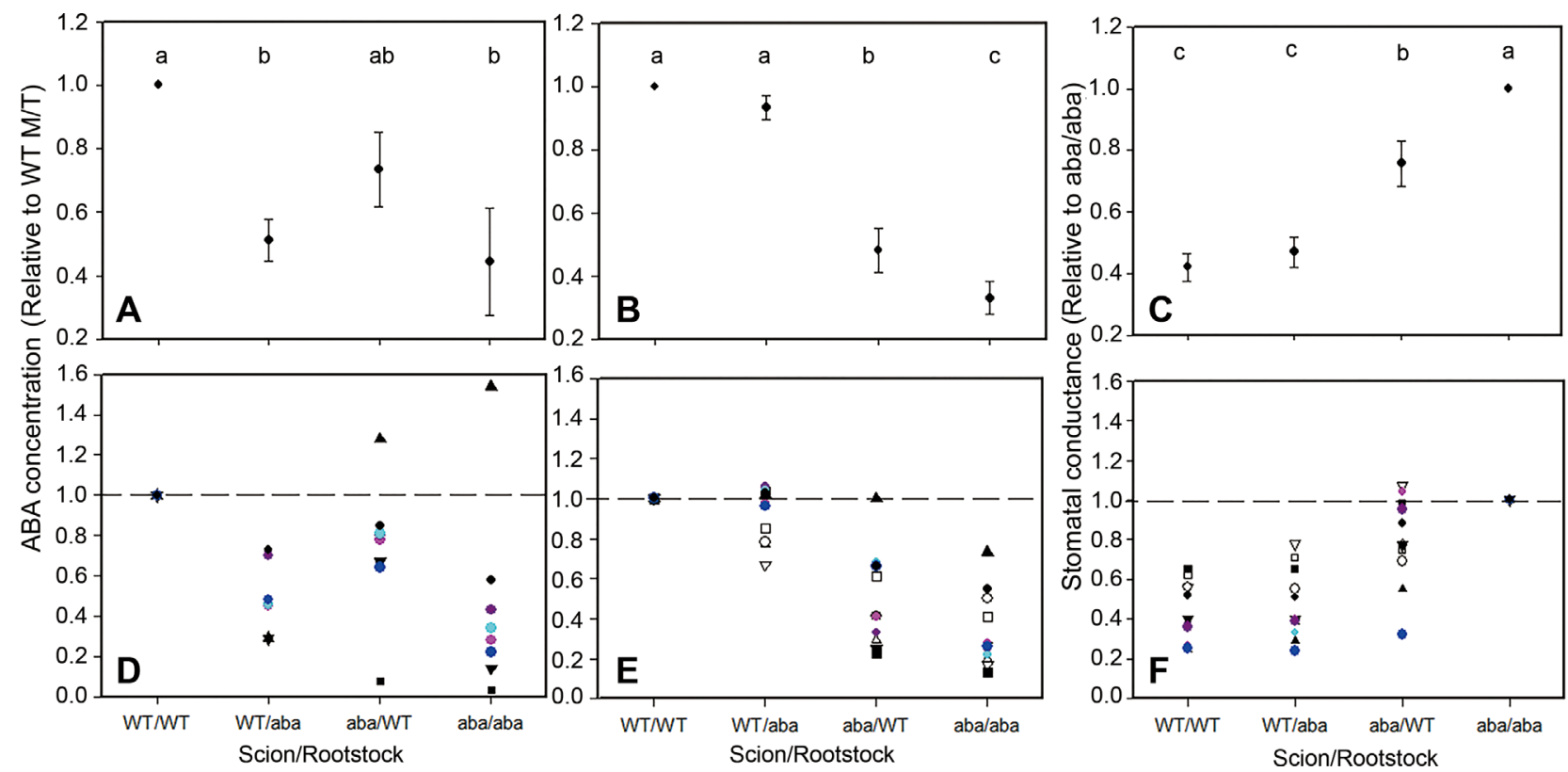

Figure 9. Relative influence of $A B A$ deficiency in self- and reciprocally grafted $A B A$-deficient (aba) and wild-type (WT) tomato plants on root $A B A$ concentration (A, D), leaf $A B A$ concentration $(B, E)$, and stomatal conductance (C, F), normalized against WT self-grafts (A, B, D, E) or ABA-deficient self-grafts (C, F)

(A) Relative influence on root $A B A$ concentration (average). (B) Relative influence on leaf $A B A$ concentration (average). (C) Relative influence on stomatal conductance (average). (D) Relative influence on root $A B A$ concentration. (E) Relative influence on leaf ABA concentration. (F) Relative influence on stomatal conductance. Each point in A-C indicates the means \pm SE of the data summarized in panels (D-F), with different letters (a, b, C) indicating significant $(P<0.05)$ differences in the normalized response. Data from the original studies and their level of replication are summarized in Table S4. Values from plants grown under low (LP; $0.2 \mathrm{mmol} / \mathrm{L}$ ) or sufficient (HP; $2.0 \mathrm{mmol} / \mathrm{L}$ ) phosphorus supply with (S) or without $75 \mathrm{mmol} / \mathrm{L} \mathrm{NaCl}$ were compiled from this study (HP, magenta circles; LP, dark magenta circles; HPS, light cyan circles; and LPS, dark cyan circles) and included in D-F. In (D), data from Manzi et al. (2015) reflect grafts with the ABA-deficient flacca mutant measured in moistened (filled triangles) and dry (filled inverted triangles) perlite; data from McAdam et al. (2016a) reflect grafts with the ABA-deficient sitiens mutant measured under well-watered conditions (filled squares); and data from Chen et al. (2002) reflect grafts with flacca measured under hydroponic conditions (filled circles), The data in (E) are as above, but with additional data from Holbrook et al. (2002) reflecting grafts with sitiens measured under well-watered (hollow triangles) and drying soil (hollow inverted triangles) conditions; and from Chen et al. (2003), reflecting grafts with flacca measured under optimal (hollow circles) and saline (hollow squares) conditions. The data in (F) also include measurements from Jones et al. (1987) reflecting grafts with sitiens at high (hollow triangles) and low (hollow inverted triangles) relative humidity, and from grafts with flacca measured in the first (hollow circles) and last (hollow squares) six hours of the photoperiod; data from Holbrook et al. (2002) reflecting grafts with sitiens measured under well-watered conditions (filled inverted triangles); data from Chen et al. (2002) reflecting grafts with flacca measured under hydroponic conditions (filled circles); data from Dodd et al. (2009) reflecting grafts with flacca measured under well-watered conditions (filled triangles); and data from Ntatsi et al. (2014) reflecting grafts with the ABA-deficient notabilis mutant measured under hydroponic conditions (filled squares).

\section{Low $\mathrm{P}$ has variable effects on the physiological effects} of salt stress

For almost all variables (except $[A B A]_{\text {root }}$ and leaf area), the salt $\times \mathrm{P}$ interaction (Table $\mathrm{S}_{5}$ ) was significant, since the effects of combined salt and $P$ deficiency were different from those predicted from the addition of the effects of the component stresses. For example, averaged across all graft combinations, shoot biomass was reduced $30 \%$ by low $P$ and $56 \%$ by salt stress, yet the combination of these stresses only decreased shoot biomass by $79 \%$ (Figure 1). Similar non-additive effects on whole plant biomass (Zribi et al. 2012) and the 
relative growth rate of wild and cultivated barley (Zribi et al. 2014) were found under combined salt $(100 \mathrm{mmol} /$ $\mathrm{L} \mathrm{NaCl}$ ) stress and $\mathrm{P}$ deprivation ( $5 \mu \mathrm{M} \mathrm{P}$ ). Moreover, since individual low $\mathrm{P}$ and salt stresses had opposing effects on foliar $A B A$ concentrations, the $[A B A]_{\text {leaf }}$ of the plants grown under control conditions and those under combined stress were similar (except in the flc/WT plants), although the combined stress substantially increased the $[A B A]_{\text {root }}$ and $[A B A]_{\text {xylem }}$ compared with the control plants (Figure 4). By contrast, combined salt and $P$ stress exacerbated the salt-induced decrease in $\Psi_{\text {leaf }}$ and $\Psi_{\text {root }}$ (Figure 3), suggesting that the diminished $A B A$ accumulation under low $P$ affects plant water relations when combined with salinity stress.

\section{Root $A B A$ accumulation is partially regulated by shoot} ABA export

Of the two abiotic stresses applied, only salinity increased the $[A B A]_{\text {root }}$ (irrespective of $P$ status), suggesting that decreased $\Psi_{\text {root }}$ (Figure 3B) stimulates ABA accumulation. Although $[A B A]_{\text {root }}$ and $\Psi_{\text {root }}$ were linearly related in salinized plants across all graft combinations (Figure $8 \mathrm{C}$ ), this relationship was the opposite of that seen when WT plants were exposed to drying soil (Puértolas et al. 2015). These contrasting relationships between $[\mathrm{ABA}]_{\text {root }}$ and $\Psi_{\text {root }}$ suggest the need for flow modelling experiments (Wolf et al. 1990; Peuke 2016) with reciprocally grafted plants, to distinguish local and long-distance effects on root ABA status.

In agreement with previous reports, WT scions increased the $[A B A]_{\text {root }}$ of flc rootstocks (Figure 4C; Manzi et al. 2015; McAdam et al. 2016a), while flc scions decreased the $[A B A]_{\text {root }}$ of WT rootstocks (Chen et al. 2002; Manzi et al. 2015). [ABA] $]_{\text {root }}$ is highly dependent on the import of precursors from the shoot during shortterm stresses (such as transplanting to dry soil; Manzi et al. 2015) or in response to defoliation or shading (Ren et al. 2007), whereas long-term experiments under steady-state conditions (as applied here) may minimize scion effects on $[A B A]_{\text {root }}$. Although published experiments reveal considerable variation in the relative magnitude of grafting effects on $[A B A]_{\text {root }}$ (Figure 9D), summarizing these data demonstrated that reciprocally grafted plants had root $A B A$ concentrations that were intermediate between the respective self-grafts (Figure $9 A)$, indicating scion modulation of $[A B A]_{\text {root }}$.

\section{Scion-dependent physiological effects on root ABA export}

In WT scions, $[A B A]_{\text {leaf }}$ was independent of root $A B A$ export (cf. Figure $4 A, B$ ), yet the physiological effects of root $A B A$ export depended on the stress(es) encountered and the physiological processes considered. The $\mathrm{g}_{\mathrm{s}}$ of WT/flc plants was almost double that of WT selfgrafts under control conditions (Figure $2 \mathrm{~A}$ ), contrary to the rootstock-independent $g_{s}$ of WT scions under individual and combined low $\mathrm{P}$ and salt stresses, which was consistent with an analysis of stomatal responses in reciprocally grafted ABA-deficient and WT tomato plants (Figure $9 \mathrm{C}$ ). While leaf area was independent of the rootstock genotype under control conditions (Figure 2B), as previously reported (Dodd et al. 2009), various stresses decreased the leaf area of WT/flc plants compared with the WT self-grafts (Figure 2B). Different physiological processes (stomatal conductance versus leaf expansion) are therefore differentially sensitive to root $A B A$ export, making it difficult to generalize on the role of root-supplied $A B A$.

Likewise, the effects of WT rootstocks on flc scions depended on the stress(es) applied. While there were limited rootstock effects on the $g_{s}$ of flc scions in nonsalinized plants, stomatal closure (near-equivalent to that of WT scions) occurred in salinized plants (Figure $2 \mathrm{~A})$. Differences in the magnitude of this stomatal phenotypic reversion are likely due to both (stressinduced) variation in root $A B A$ export (Figure $4 B$ ) and catabolism of xylem-supplied $A B A$ in the leaves (Gowing et al. 1993). Stomatal phenotypic reversion of ABAdeficient scions by WT rootstocks varies considerably (Albacete et al. 2015), yet the consensus response in tomato is a decreased $g_{s}$ when compared with the ABAdeficient self-grafts (Figure $9 \mathrm{C}$ ). Moreover, WT rootstocks partially phenotypically reverted the leaf area of flc under all treatments except the combined salt and low $\mathrm{P}$ stresses (Figure 2B). In well-watered plants, this phenotypic reversion was independent of $\Psi_{\text {leaf }}$ and associated with the direct effects of increased root $A B A$ export and the normalization of shoot ethylene relations (Dodd et al. 2009). Taken together, a rootstock's ability to influence scion physiology depends on whether it affects $[A B A]_{\text {leaf }}$ (cf. Figure $9 B, C$ ), which is moderated by the rootstock genotype and the environmental stress(es) encountered.

Pairwise comparisons of self- and reciprocal grafts of different ABA-deficient mutants and WT plants grown 
under different environmental stresses revealed divergent physiological responses to root- or shoot-supplied $A B A$, ranging from no measurable effect to substantial phenotypic reversion (Figure $9 \mathrm{D}-\mathrm{F}$ ). Despite these differences, summarizing the available data revealed a consensus view (Figure 9A-C) that long-distance ABA transport has limited physiological effects unless it modifies local ABA status, which occurs under some specific stresses.

\section{MATERIALS AND METHODS}

\section{Plant material and culture}

Seed of isogenic wild-type (WT; cv. Ailsa Craig) and flc genotypes of tomato (Solanum lycopersicum Mill.) were obtained from the Tomato Genetic Resources Centre (UC Davis, USA). The flc genotype is impaired in the oxidation of ABA-aldehyde to ABA (Taylor et al. 1988), resulting in leaf $A B A$ concentrations of only $30 \%$ of the WT level (Netting et al. 2012). The experiments were carried out in a naturally lit glasshouse compartment $(5 \times 3 \mathrm{~m})$ at the Lancaster Environment Centre, with supplementary lighting provided (for a photoperiod of 06:00-20:00h) using high pressure sodium lamps (Osram Plantastar 600W; Munich, Germany) when the ambient photosynthetic photon flux density was less than $500 \mu \mathrm{mol} \cdot \mathrm{m}^{-2} \cdot \mathrm{s}^{-1}$. The daily maximum temperature in the greenhouse was $30^{\circ} \mathrm{C}$, with a minimum night temperature of $17^{\circ} \mathrm{C}$. Environmental conditions in the center of the glasshouse were recorded using an Ektron II (HortiMaX Growing Solutions, Pijnacker, The Netherlands). Plants were randomly arranged on the glasshouse bench, and the position of each plant was changed daily.

Seeds were sown in seedling trays filled with a 1:1 mixture of sand (Grade 16/30; Sibelco UK Ltd., Sandbach, UK) and vermiculite (fine grade $1.0-3.0 \mathrm{~mm}$, density approximately $100 \mathrm{~kg} \cdot \mathrm{m}^{-3}$, neutral $\mathrm{pH}$ 6.0-7.0; William Sinclair Horticulture Ltd., Lincoln, UK). A single seed was sown into each separate compartment $(3 \mathrm{~cm}$ deep $\times$ $2 \mathrm{~cm} \times 2 \mathrm{~cm}$ ). After $12 \mathrm{~d}$, when the cotyledons and one true leaf had emerged, plants were transferred to individual $0.9 \mathrm{~L}$ cylindrical pots $(6.9 \mathrm{~cm}$ diameter $\times 24 \mathrm{~cm}$ height) containing the same substrate. The pots were plastic tubes with a mesh base, designed to fit in a pressure chamber (Puértolas et al. 2013). Following transplantation, the plants were immediately watered with tap water. The pot surface was covered with black tape to minimize evaporation from the substrate, with a 1 $\mathrm{cm}^{2}$ hole in the center to allow the plant stems to protrude.

To ensure that the stem diameters were of a similar size for grafting, 2.0-week-old WT seedlings and 3.5-week-old flc seedlings were used for self- and reciprocal grafts. High phosphorus (HP) Hoagland solution ( $2 \mathrm{mmol} / \mathrm{L} \mathrm{P}, \mathrm{pH} 6.0$ ) was supplied every $4 \mathrm{~d}$ to maintain growth. Extra irrigation (tap water) was supplied daily according to transpirational demands, to avoid wilting. The HP solution comprised (in mmol/L) 5 $\mathrm{KNO}_{3}, 5 \mathrm{Ca}\left(\mathrm{NO}_{3}\right)_{2} \cdot 4 \mathrm{H}_{2} \mathrm{O}, 2 \mathrm{MgSO}_{4} \cdot 7 \mathrm{H}_{2} \mathrm{O}, 3 \mathrm{NaFe}-\mathrm{EDTA}$, $1 \mathrm{NH}_{4} \mathrm{NO}_{3}, 2 \mathrm{KH}_{2} \mathrm{PO}_{4}$, and (in $\left.\mu \mathrm{M}\right) 2 \mathrm{~B}, 2 \mathrm{Mn}, 2 \mathrm{Zn}, 2 \mathrm{Cu}$, and $2 \mathrm{Mo}$. The LP (low phosphorus) solution ( $0.2 \mathrm{mmol} / \mathrm{L}$ $\mathrm{P}, \mathrm{pH}$ 6.0) was prepared by substituting in $0.2 \mathrm{mmol} / \mathrm{L}$ $\mathrm{KH}_{2} \mathrm{PO}_{4}$, as previously described (Wang et al. 2016). To ensure the HP and LP solutions had similar $\mathrm{K}^{+}$and nitrogen concentrations, the LP solution also contained $6.8 \mathrm{mmol} / \mathrm{L} \mathrm{KNO}$ and $0.1 \mathrm{mmol} / \mathrm{L} \mathrm{NH}_{4} \mathrm{NO}_{3}$ to compensate for the lower $\mathrm{KH}_{2} \mathrm{PO}_{4}$ concentration.

Graft unions were established just below the cotyledonary node, as previously described (Dodd et al. 2009). These grafted plants were irrigated with HP or LP solutions daily at 17:00-18:00 h. After irrigation for three weeks with HP or LP solutions, half the plants in each $\mathrm{P}$ treatment were irrigated with the same solutions supplemented with $75 \mathrm{mmol} / \mathrm{L} \mathrm{NaCl}$. Nonsalinized plants with WT scions received extra distilled water daily at 09:00 $\mathrm{h}$, while non-salinized plants with flc scions were also irrigated at 12:00 h and 14:30 h (according to the transpirational needs of the plant) to avoid excessive drying of the substrate. Salinized plants only received the daily salt solutions. There were four treatments: control (HP, no salt), low P (LP, no salt), salt (HP, salt), and combined stress (LP, salt).

\section{Physiological measurements, xylem sap collection, and analyses}

After $9 \mathrm{~d}$ of salt treatment, whole plant transpiration was estimated gravimetrically by weighing the pots between 09:00 $\mathrm{h}$ and 12:00 h. During this time, gas exchange of the sixth (fully expanded) leaf (from the top of the plant) was determined using infra-red gas analysis (Li-6400; Li-COR Inc., NE, USA). Leaves of six plants per graft combination per treatment were allowed to equilibrate to the ambient (glasshouse) temperature, in $400 \mathrm{ppm}$ $\mathrm{CO}_{2}$ and with a photosynthetic photon flux density 
(500 $\left.\mu \mathrm{mol} \mathrm{m}^{-2} \mathrm{~s}^{-1}\right)$ for $4 \mathrm{~min}$ before data were recorded. The water potentials of the leaves were determined using a pressure chamber (Model: 3005; Soilmoisture Equipment Corp, CA, USA). About $3 \mathrm{~cm}^{2}$ of fresh tissue from the third completely expanded leaf from the shoot apex was frozen in liquid nitrogen and stored at $-20^{\circ} \mathrm{C}$. The shoot was then severed at the stem base (below the graft union), the cut surface rinsed two to three times with distilled water to remove any contaminating cell debris, and then blotted dry with filter paper. Root water potential was investigated using a pressure chamber, and was determined to be the pressure at which sap exuded from the cut surface. When there was spontaneous sap exudation from the cut surface (without applying pressure), root water potential was considered to be o MPa. Root xylem sap was collected into preweighed Eppendorf tubes. Sufficient overpressure was applied to ensure the xylem sap flow rate closely matched the whole plant transpiration rate. The collected root xylem sap was immediately stored at $-20^{\circ} \mathrm{C}$ for $\mathrm{ABA}$ analysis. Roots were quickly ( $<1 \mathrm{~min}$ ) and carefully removed from the pot and washed, and $1 \mathrm{~g}$ fresh root tissue was frozen using liquid nitrogen and stored at $-20^{\circ} \mathrm{C}$.

Total leaf area was recorded using a Li-3100 Area Meter (Li-COR Inc.). Shoots and roots were oven-dried and weighed, then the total phosphorus $(\mathrm{P})$ and sodium $\left(\mathrm{Na}^{+}\right)$concentrations were measured in these tissues. Approximately $0.1 \mathrm{~g}$ of each sample was ground into powder and digested in $\mathrm{H}_{2} \mathrm{SO}_{4}(98 \%)-\mathrm{H}_{2} \mathrm{O}_{2}(30 \%)$ with $4: 1$ $(\mathrm{V} / \mathrm{V})$. The $\mathrm{P}$ content in the digested solution was measured as previously described (Wasaki et al. 2003). The $\mathrm{Na}^{+}$concentration in the digested solution was determined using a flame photometer (FP640; Shanghai Jingke Scientific Instrument Co., Ltd., Shanghai, China).

The ABA concentrations of the leaf, root, and xylem sap were measured using the radioimmunoassay method as previously described (Quarrie et al. 1988), with minor modifications. Frozen leaf and root tissues were freeze-dried then ground into powder. Approximately $20 \mathrm{mg}$ dry leaf tissue or $30 \mathrm{mg}$ dry root tissue were mixed with distilled water at a ratio of 1:70 (WT leaves), 1:50 (flc leaves), or 1:25 (root samples), respectively, and then shaken at $4^{\circ} \mathrm{C}$ overnight to extract $A B A$. The homogenates were centrifuged at 15,000 rpm for $5 \mathrm{~min}$, and the supernatant was directly used for the ABA assay.

\section{Statistical analysis}

Data were subjected to four-way ANOVA (analysis of variance) to investigate the effects of the scion, rootstock, salinity, and phosphorus concentration (Table S5). Each experiment was repeated four times, with six biological replicates in each group. Across all treatments and graft combinations, the means were compared using Duncan's multiple range tests at the $5 \%$ level of probability. Linear regressions established significant $(P<0.05)$ relationships between variables (Table S3).

\section{ACKNOWLEDGEMENTS}

This study was supported by the National Natural Science Foundation of China (31300327) and Excellent Young Scientist Foundation of Henan University (yqpy20140030). ICD and CdO thank the EU ROOTOPOWER (289365) project for supporting research on grafting. We thank the Tomato Genetic Resources Centre for seed provision.

\section{AUTHOR CONTRIBUTIONS}

Concept and experimental design: W.L. and I.C.D. Performed experiment: W.L. with technical guidance from C.d.O. Analyzed data: W.L. Manuscript preparation: W.L. with editorial contributions from C.d.O. and I.C.D. All authors have read and approved the submitted manuscript.

\section{REFERENCES}

Albacete A, Ghanem ME, Martínez-Andújar C, Acosta M, Sanchez-Bravo J, Martinez V, Lutts S, Dodd IC, PérezAlfocea $\mathrm{F}$ (2008) Hormonal changes in relation to biomass partitioning and shoot growth impairment in salinised tomato (Solanum lycopersicum L.) plants. J Exp Bot 59: 4119-4131

Albacete A, Martínez-Andújar C, Martínez-Pérez A, Thompson $A J$, Dodd IC, Pérez-Alfocea $F$ (2015) Unravelling rootstock $x$ scion interactions to improve food security. J Exp Bot 66: 2211-2226

Atkinson NJ, Urwin PE (2012) The interaction of plant biotic and abiotic stresses: From genes to the field. J Exp Bot 63: 3523-3543 
Awad AS, Edwards DG, Campbell LC (1990) Phosphorus enhancement of salt tolerance of tomato. Crop Sci 30: 123-128

Biddinger EJ, Liu C, Joly RJ, Raghothama KG (1998) Physiological and molecular responses of aeroponically grown tomato plants to phosphorus deficiency. J Am Soc Hortic Sci 123: 330-333

Chen GX, Fu XP, Lips SH, Sagi M (2003) Control of plant growth resides in the shoot, and not in the root, in reciprocal grafts of flacca and wild-type tomato (Lycopersicon esculentum), in the presence and absence of salinity stress. Plant Soil 256: 205-215

Chen GX, Lips SH, Sagi M (2002) Biomass production, transpiration rate and endogenous abscisic acid levels in grafts of flacca and wild-type tomato (Lycopersicon esculentum). Funct Plant Biol 29: 1329-1335

Christmann A, Weiler EW, Steudle E, Grill E (2007) A hydraulic signal in root-to-shoot signalling of water shortage. Plant J 52: $167-174$

Cornish K, Zeevaart JAD (1985) Abscisic acid accumulation by roots of Xanthium strumarium L. and Lycopersicon esculentum Mill. in relation to water stress. Plant Physiol 79: 653-658

Dodd IC, Theobald JC, Richer SK, Davies WJ (2009) Partial phenotypic reversion of ABA-deficient flacca tomato (Solanum lycopersicum) scions by a wildtype rootstock: Normalising shoot ethylene relations promotes leaf area but does not diminish whole plant transpiration rate. J Exp Bot 60: 4029-4039

Fujita K, Okada M, Lei K, Ito J, Ohkura K, Adu-Gyamfi JJ, Mohapatra PK (2003) Effect of P-deficiency on photoassimilate partitioning and rhythmic changes in fruit and stem diameter of tomato (Lycopersicon esculentum) during fruit growth. J Exp Bot 54: 2519-2528

García MJ, Romera FJ, Lucena C, Alcántara E, Pérez-Vicente R (2015) Ethylene and the regulation of physiological and morphological responses to nutrient deficiencies. Plant Physiol 169: 51-60

Gowing DJG, Jones HG, Davies WJ (1993) Xylem-transported abscisic acid: The relative importance of its mass and its concentration in the control of stomatal aperture. Plant Cell Environ 16: 453-459

Grattan SR, Grieve CM (1999) Mineral nutrient acquisition and response by plants grown in saline environments. Agric Ecosyst Environ 38: 275-300

Holbrook NM, Shashidhar VR, James RA, Munns R (2002) Stomatal control in tomato with ABA-deficient roots: Response of grafted plants to soil drying. J Exp Bot 53: 1503-1514

luchi S, Kobayashi M, Taji T, Naramoto M, Seki M, Kato T, Shinozaki K (2001) Regulation of drought tolerance by gene manipulation of 9-cis-epoxycarotenoid dioxygenase, a key enzyme in abscisic acid biosynthesis in Arabidopsis. Plant J 27: 325-333

Jeschke WD, Peuke AD, Pate JS, Hartung W (1997) Transport, synthesis and catabolism of abscisic acid (ABA) in intact plants of castor bean (Ricinus communis L.) under phosphate deficiency and moderate salinity. J Exp Bot 148: $1737-1747$

Jones HG, Sharp CS, Higgs KH (1987) Growth and water relations of wilty mutants of tomato (Lycopersicon esculentum Mill.). J Exp Bot 38: 1848-1856

Kudoyarova GR, Dodd IC, Veselov DS, Rothwell SA, Veselov SY (2015) Common and specific responses to availability of mineral nutrients and water. J Exp Bot 66: 2133-2144

Linforth RST, Bowman WR, Griffin DA, Marples BA, Taylor IB (1987) 2-trans-ABA alcohol accumulation in the wilty tomato mutants flacca and sitiens. Plant Cell Environ 10: 599-606

Mäkelä P, Munns R, Colmer TD, Peltonen-Sainio P (2003) Growth of tomato and an ABA-deficient mutant (sitiens) under saline conditions. Physiol Plant 117: 58-63

Manzi M, Lado J, Rodrigo MJ, Zacarías L, Arbona V, GómezCadenas A (2015) Root ABA accumulation in long-term water-stressed plants is sustained by hormone transport from aerial organs. Plant Cell Physiol 56: 2457-2466

Martínez-Andújar C, Ruiz-Lozano JM, Dodd IC, Albacete A, Pérez-Alfocea $F$ (2017) Hormone and nutrient export from tomato rootstocks mediate contrasting scion performance under low-phosphorus nutrition. Front Plant Sci 8: 533

McAdam SAM, Brodribb TJ, Ross JJ (2016a) Shoot-derived abscisic acid promotes root growth. Plant Cell Environ 39: 652-659

McAdam SAM, Sussmilch FC, Brodribb TJ (2016b) Stomatal responses to vapour pressure deficit are regulated by high speed gene expression in angiosperms. Plant Cell Environ 39: 485-491

Mittler R (2006) Abiotic stress, the field environment and stress combination. Trends Plant Sci 11: 15-19

Mohammad M, Shibli R, Ajlouni M, Nimri L (1998) Tomato root and shoot responses to salt stress under different levels of phosphorus nutrition. J Plant Nutr 21: 1667-1680

Mulholland BJ, Taylor IB, Jackson AC, Thompson AJ (2003) Can $A B A$ mediate responses of salinity stressed tomato? Environ Exp Bot 50: 17-28

Netting AG, Theobald JC, Dodd IC (2012) Xylem sap collection and extraction methodologies to determine in vivo concentrations of $A B A$ and its bound forms by gas chromatography-mass spectrometry (GC-MS). Plant Methods 8: 11-24

Ntatsi G, Savvas D, Huntenburg K, Druege U, Hincha DK, Zuther E, Schwarz D (2014) A study on ABA involvement in the response of tomato to suboptimal root temperature using reciprocal grafts with notabilis, a null mutant in the ABA-biosynthesis gene LeNCED. Environ Exp Bot 97: 11-21

Peuke AD (2016) ABA flow modelling in Ricinus communis exposed to salt stress and variable nutrition. J Exp Bot 67: 5301-5311

Puertolas J, Alcobendas R, Alarcón JJ, Dodd IC (2013) Longdistance abscisic acid signalling under different vertical 
soil moisture gradients depends on bulk root water potential and average soil water content in the root zone. Plant Cell Environ 36: 1465-1475

Puértolas J, Conesa MR, Ballester C, Dodd IC (2015) Local root abscisic acid (ABA) accumulation depends on the spatial distribution of soil moisture in potato: Implications for ABA signalling under heterogeneous soil drying. J Exp Bot 66: 2325-2334

Quarrie SA, Whitford PN, Appleford NEJ, Wang TL, Cook SK, Henson IE, Loveys BR (1988) A monoclonal antibody to (S)-abscisic acid: Its characterisation and use in a radioimmunoassay for measuring abscisic acid in crude extracts of cereal and lupin leaves. Planta 173: 330-339

Radin JW (1984) Stomatal responses to water stress and to abscisic acid in phosphorus-deficient cotton plants. Plant Physiol 76: 392-394

Radin JW, Matthews MA (1989) Water transport properties of cortical cells in roots of nitrogen-and phosphorus-deficient cotton seedlings. Plant Physiol 89: 264-268

Ren HB, Gao ZH, Chen L, Wei KF, Liu J, Fan YJ, Davies WJ, Jia WS, Zhang JH (2007) Dynamic analysis of ABA accumulation in relation to the rate of $A B A$ catabolism in maize tissues under water deficit. J Exp Bot 58: 211-219

Rock CD, Heath TG, Gage DA, Zeevaart JAD (1991) Abscisic alcohol is an intermediate in abscisic acid biosynthesis in a shunt pathway from abscisic aldehyde. Plant Physiol 97: 670-676

Rothwell SA, Elphinstone ED, Dodd IC (2015) Liming can decrease legume crop yield and leaf gas exchange by enhancing root to shoot ABA signalling. J Exp Bot 66: 2335-2345

Sagi M, Fluhr R, Lips SH (1999) Aldehyde oxidase and xanthine dehydrogenase in a flacca tomato mutant with deficient abscisic acid and wilty phenotype. Plant Physiol 120: 571-577

Schachtman DP, Goodger JQD (2008) Chemical root to shoot signaling under drought. Trends Plant Sci 13: 281-287

Shabala S, White RG, Djordjevic MA, Ruan YL, Mathesius U (2016) Root-to-shoot signalling: Integration of diverse molecules, pathways and functions. Funct Plant Biol 43: 87-104

Sharp RE, LeNoble ME, Else MA, Thorne ET, Gherardi F (2000) Endogenous $A B A$ maintains shoot growth in tomato independently of effects on plant water balance: Evidence for an interaction with ethylene. J Exp Bot 51: 1575-1584

Simonneau T, Barrieu P, Tardieu F (1998) Accumulation rate of $A B A$ in detached maize roots correlates with root water potential regardless of age and branching order. Plant Cell Environ 21: 1113-1122

Sobeih WY, Dodd IC, Bacon MA, Grierson D, Davies WJ (2004) Long-distance signals regulating stomatal conductance and leaf growth in tomato (Lycopersicon esculentum) plants subjected to partial rootzone drying. J Exp Bot 55: 2353-2363

Speirs J, Binney A, Collins M, Edwards E, Loveys B (2013) Expression of $\mathrm{ABA}$ synthesis and metabolism genes under different irrigation strategies and atmospheric VPDs is associated with stomatal conductance in grapevine (Vitis vinifera L. CV Cabernet Sauvignon). J Exp Bot 64: 1907-1916

Thompson AJ, Andrews J, Mulholland BJ, McKee JM, Hilton HW, Horridge JS, Taylor IB (2007) Overproduction of abscisic acid in tomato increases transpiration efficiency and root hydraulic conductivity and influences leaf expansion. Plant Physiol 143: 1905-1917

Wang YS, Jensen LS, Magid J (2016) Differential responses of root and root hair traits of spring wheat genotypes to phosphorus deficiency in solution culture. Plant Soil Environ 62: 540-546

Wasaki J, Yonetani R, Kuroda S, Shinano T, Yazaki J, Fujii F, Kishimoto N (2003) Transcriptomic analysis of metabolic changes by phosphorus stress in rice plant roots. Plant Soil Environ 26: 1515-1523

Wolf O, Jeschke WD, Hartung W. 1990. Long distance transport of abscisic acid in $\mathrm{NaCl}$-treated intact plants of Lupinus albus. J Exp Bot 41: 593-600

Visentin I, Vitali M, Ferrero $M$, Zhang $Y$, Ruyter-Spira C, Novak O, Strnad M, Lovisolo C, Schubert A, Cardinale F (2016) Low levels of striglactones in roots as a component of the systemic signal of drought stress in tomato. New Phytol 212: 954-963

Xu G, Zhang Y, Sun JN, Shao HB (2016) Negative interactive effects between biochar and phosphorus fertilization on phosphorus availability and plant yield in saline sodic soil. Sci Total Environ 568: 910-915

Zdunek-Zastocka E, Sobczak M (2013) Expression of Pisum sativum $\mathrm{PSAO}_{3}$ gene, which encodes an aldehyde oxidase utilizing abscisic aldehyde, is induced under progressively but not rapidly imposed drought stress. Plant Physiol Biochem 71: 57-66

Zhang JH, Davies WJ (1989) Abscisic acid produced in dehydrating roots may enable the plant to measure the water status of the soil. Plant Cell Environ 12: 73-81

Zhang JH, Jia WS, Yang JC, Ismail AM (2006) Role of ABA in integrating plant responses to drought and salt stresses. Field Crop Res 97: 111-119

Zribi OT, Houmani H, Kouas S, Slama I, Ksouri R, Abdelly C (2014) Comparative study of the interactive effects of salinity and phosphorus availability in wild (Hordeum maritimum) and cultivated barley (H. vulgare). J Plant Growth Regul 33: 860-870

Zribi OT, Labidi N, Slama I, Debez A, Ksouri RH, Rabhi M, Smaoui A, Abdelly C (2012) Alleviation of phosphorus deficiency stress by moderate salinity in the halophyte Hordeum maritimum L. Plant Growth Regul 66: 75-85 


\section{SUPPORTING INFORMATION}

Additional Supporting Information may be found online in the supporting information tab for this article: http:// onlinelibrary.wiley.com/doi/10.1111/jipb.12605/suppinfo Table S1. Leaf and root phosphorus concentrations of grafted combinations under different phosphate/salt conditions
Table S2. Leaf and root $\mathrm{Na}^{+}$concentrations of grafted combinations under different phosphate/salt conditions

Table S3. Linear correlation coefficient between parameters with $r^{2}$ and asterisks for $P$ values

Table S4. Data from the original studies and their level of replication

Table S5. Analysis of variance for the data presented

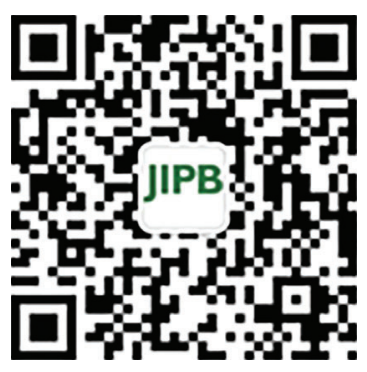

Scan using WeChat with your smartphone to view JIPB online

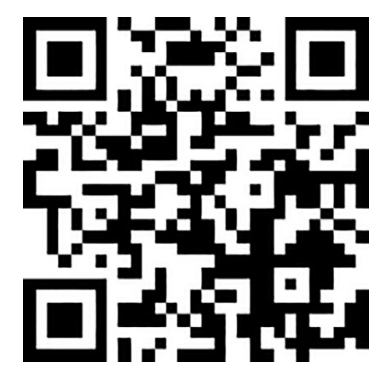

Scan with iPhone or iPad to view JIPB online 